\title{
Effects of light intensity on yield components, carbohydrate economy and cell-wall constituents in spring barley (Hordeum distichum L.)
}

\section{J. ELLEN \& H. VAN OENE}

Department of Field Crops and Grassland Science, Wageningen Agricultural University, Haarweg 333, NL 6709 RZ Wageningen, Netherlands

Received 26 October 1988; accepted 19 December 1988

\begin{abstract}
The effects of light intensity $\left(129,86\right.$ and $\left.37 \mathrm{~W} \mathrm{~m}^{-2}\right)$ after spikelet initiation on development, yield and chemical composition were studied in spring barley, Hordeum distichum cv. Trumpf, under controlled conditions. Reducing the light intensity resulted in fewer shoots per plant, prolonged the leaf area duration, lowered the specific leaf weight and delayed shoot and ear development. The light intensity strongly influenced the number of aborted spikelets, the number of kernels per ear and the 1000-grain weight. During leaf, stem and ear development the content and amount of water-soluble carbohydrates (WSC) in leaves plus stems decreased. At the same time there was a strong increase in content and amount of cellwall constituents (CWC), especially in leaves and in stems. This implies that the formation of CWC requires a large consumption of WSC. Reducing the light intensity diminished the production of WSC and CWC appreciably. The content (\%) of WSC in stems at anthesis correlated well $(r=0.68)$ with the number of kernels per ear at final harvest, calculated over main shoot, first and second tillers. The high amount of WSC in the stems of the plants at the two highest light intensities at maturity implies an insufficient storage capacity in the kernels.
\end{abstract}

Keywords: spring barley, spikelet development, specific leaf weight, harvest index, watersoluble carbohydrates, Hordeum distichum cv. Trumpf

\section{Introduction}

The growth period of spring barley (Hordeum distichum L.) from seedling to anthesis is about 80-100 days. The basis for plant and crop production is laid in this period (Kirby, 1977; Gallagher 1979; Appleyard et al., 1982).

Light affects the rate of development and also the number of spikelets per ear. Artificially manipulating light intensity during the phase of ear development can change the numbers of spikelets and kernels per ear (Dougherty et al., 1975; Fisher \& Stockman, 1980). Grains initiated early tend to monopolize the available and later formed carbohydrates (Rawson \& Evans, 1970; Sofield et al., 1977).

In a field experiment in 1985 (Ellen, unpublished), it was also observed that low light intensity during the phase of ear development resulted in a marked reduction 
in number of spikelets per ear. To investigate this effect of light intensity further, a pot experiment was set up under controlled environmental conditions. In this experiment the effect of differences in light intensity, started after spikelet initiation, on shoot and ear development, water-soluble carbohydrate (WSC) content and ultimately on number of kernels per ear was studied. This more detailed study of the economy of water-soluble carbohydrates and cell-wall constituents (CWC) in the plants during the phase of ear development was intended to reveal possible causes of spikelet abortion. The results of this experiment will be discussed in this paper.

\section{Materials and methods}

An experiment with three light intensities, 129 (L1), 86 (L2) and 37 (L3) $\mathrm{W} \mathrm{m}^{-2}$ (wavelength 400-700 nm; measured at plant height) was carried out in a phytotron. The lamps used were Philips SGR 200 and Philips SON-T $400 \mathrm{~W}$ high-pressure sodium lamps and Philips HPI-T $400 \mathrm{~W}$ metal-halide lamps. They were air-cooled, and mounted above a glass ceiling. The phytotron was divided into three compartments, each with its own light intensity. The replicates were inside these compartments. The different light intensities were achieved by screening parts of the light ceiling with aluminium mesh. The light treatments were screened off from each other by opaque white plastic curtains, hung parallel to the direction of the air flow.

During the whole growth period a photoperiod of 14 hours and a day temperature of $19^{\circ} \mathrm{C}(12 \mathrm{~h})$ and night temperature of $9{ }^{\circ} \mathrm{C}(12 \mathrm{~h})$ were maintained. The relative humidity of the air was $90 \%$ constantly.

Five-litre pots $\left(16\right.$ pots per $\left.\mathrm{m}^{2}\right)$ were filled with $5.25 \mathrm{~kg}$ clay soil. Twenty seeds of spring barley, Hordeum distichum cv. Trumpf, were sown per pot at a depth of 1.5 $\mathrm{cm}$. Six days after sowing, $95 \%$ of the plants had emerged. This day was designated day 0 (zero). On day 5 , the seedlings were thinned to 15 plants per pot. The pots were rotated around each compartment weekly.

Mineral nutrients were supplied in three equal doses on the 4th (GS 0), 28th (GS 30) and 50th day (GS 35) after sowing (growth stages (GS) after Zadoks et al., 1974), i.e. $-2,26$ and 48 days after emergence, respectively. The total supply of nutrients was (in mg per pot) $2016 \mathrm{~N}$ (ratio $\mathrm{NH}_{4}{ }^{+} / \mathrm{NO}_{3}{ }^{-}$was $1: 2.5$ ), $434 \mathrm{P}, 1248 \mathrm{~K}, 720$ $\mathrm{Ca}$ and $144 \mathrm{Mg}$. Micro-elements were supplied once.

Up until day 40 (GS 34), all plants were grown at the same light intensity of $129 \mathrm{~W}$ $\mathrm{m}^{-2}$. On that day the three light regimes were begun and these were maintained for the remainder of the growth period (until final harvest). Day 40 was chosen for starting the different light intensities because the spikelet initiation of the main stem and first two tillers was completed by then.

From day 15 until day 40, three pots were harvested weekly. From day 40 onwards, two pots were harvested weekly per light level, except during the grain-filling period, when no pots were harvested. Five plants per harvested pot were split into main shoot, first and second tiller; the remaining shoots were pooled together. Per harvest, a few shoots were taken (usually from two plants per light intensity), and their spikes were dissected and the spikelets were counted. Fresh weight, number of shoots per plant, leaf area per shoot, dry weight of leaves, stems and dead 
material were recorded. In the two harvests just before anthesis, the number of spikes per plant and the fresh and dry weights of spikes per shoot were also determined. The roots were cut off and washed, and their dry weight was recorded. The final harvest was on day 144 (all plants were ripe then); five pots were harvested per light intensity. The number and dry weight of kernels were also recorded during this final harvest.

After each harvest the samples taken were dried for 24 hours at $70{ }^{\circ} \mathrm{C}$ and, after weighing, the plant material from each replicate was pooled per plant organ for the chemical analysis of water-soluble carbohydrates (WSC; for method, see Spiertz, 1977). The cell-wall constituents (CWC) of some samples were also analyzed (for method, see Goering \& van Soest, 1970).

\section{Results}

\section{Rate of development}

Plants in the lower light intensities developed more slowly (Table 1). The growth rate and rate of development of the tillers also differed. Later-formed shoots and ears developed faster than the main stems and weighed less.

\section{Number of spikelets per ear}

The double ridge stage of the main stems had been reached by day 20 . The number of spikelets per ear was counted for the first time on day 43 , three days after the different light intensities had been established. Table 2 gives the numbers of spikelets per ear at important moments in ear formation. Most spikelets aborted before anthesis (in GS 39). The numbers of aborted spikelets per ear, averaged over the main stem and the first two tillers were 17.3, 15.3 and 20.7 for L1, L2 and L3 plants, respectively. During grain set few spikelets aborted. Averaged over main stem, first and second tiller, $60 \%(\mathrm{~L} 1), 59 \%$ (L2) and $51 \%$ (L3) of the initially formed spikelet primordia appeared to have produced full-grown kernels.

\section{Leaf area and specific leaf weight (SLW)}

Leaf area per plant peaked at about day 60 (GS 45). Differences in leaf area per plant between the three light intensities were small and leaf area was, on average, $346 \mathrm{~cm}^{2}$ per plant at that time. After GS 45 the leaves started to die. On day 78 the leaf area values had already fallen to 212,252 and $301 \mathrm{~cm}^{2}$ per plant for L1, L2 and L3 plants, respectively. The leaves of L2 plants, and even more so, those of L3 plants, remained green much longer during grain filling.

Specific leaf weight (SLW) was influenced strongly by the level of light (Fig. 1). On day 78 the values for the SLW of the main stems of L2 and L3 plants were only $75 \%$ and $62 \%$, respectively, of the SLW of the main stems of L1 plants. In the second tillers a similar effect could be seen, but the SLW values were generally about $10 \%$ below those of the main stems. 


\section{J. ELLEN AND H. VAN OENE}

Table 1. Rate of development of the main shoot at three light intensities (growth stages of Zadoks et al., 1974).

\begin{tabular}{llll}
\hline Days after emergence & L1 & L2 & L3 \\
15 & 23 & - & - \\
22 & 28 & - & - \\
29 & 31 & - & - \\
36 & 33 & - & - \\
40 (start of L2L3) & & & 34 \\
43 & 34 & 34 & 34 \\
50 & 35 & 35 & 36 \\
57 & 41 & 37 & 40 \\
64 & 45 & 43 & 45 \\
71 & 57 & 50 & 53 \\
78 (finish flowering L1) & 68 & 57 & 80 \\
98 & 86 & 83 & 85 \\
113 & 91 & 87 & 87 \\
123 & 93 & 90 & \\
144 (final harvest) & & & \\
\hline
\end{tabular}

Table 2. Maximum number of spikelets, aborted spikelets, number of fertile spikelets (GS 39) and number of kernels per ear (final harvest) at three light intensities.

\begin{tabular}{|c|c|c|c|c|c|c|c|c|c|c|c|c|}
\hline & \multicolumn{3}{|c|}{$\begin{array}{l}\text { Number of spike- } \\
\text { let primordia }\end{array}$} & \multicolumn{3}{|c|}{$\begin{array}{l}\text { Aborted } \\
\text { spikelets }\end{array}$} & \multicolumn{3}{|c|}{$\begin{array}{l}\text { Number of } \\
\text { fertile spikelets }\end{array}$} & \multicolumn{3}{|c|}{ Number of kernels } \\
\hline & L1 & L2 & L3 & L1 & L2 & L3 & L1 & $\mathrm{L} 2$ & L3 & L1 & $\mathrm{L} 2$ & L3 \\
\hline Main stem & 50 & 50 & 50 & 18 & 16 & 22 & 32 & 34 & 28 & 31.0 & 29.2 & 26.1 \\
\hline Tiller 1 & 48 & 44 & 44 & 16 & 14 & 20 & 32 & 30 & 24 & 28.4 & 27.2 & 23.3 \\
\hline Tiller 2 & 44 & 44 & 44 & 18 & 16 & 20 & 26 & 28 & 24 & 25.6 & 25.0 & 21.2 \\
\hline
\end{tabular}

Table 3. Plant dry matter yield (without roots), grain yield, harvest index, yield components, and moisture content in the kernels, at three light intensities.

\begin{tabular}{lcccc}
\hline & L1 & L2 & L3 & Fisher test \\
Total dry matter yield (g/plant) & 14.5 & 12.2 & 9.1 & $* * * *$ \\
Kernel yield (dry matter; g/plant) & 6.8 & 6.0 & 3.6 & $* * * *$ \\
Harvest index (HI) & 0.47 & 0.49 & 0.40 & $* * * *$ \\
Number of ears/plant & 4.9 & 4.6 & 3.8 & $* * * *$ \\
Number of grains/ear & 26.7 & 26.1 & 23.6 & $* * * *$ \\
1000-kernel weight (dry matter; g) & 51.6 & 50.1 & 40.2 & $* * *$ \\
Moisture content (\%) in kernels & 13.1 & 20.9 & 27.0 & $* * * *$ \\
\hline
\end{tabular}

****P<0.001. 

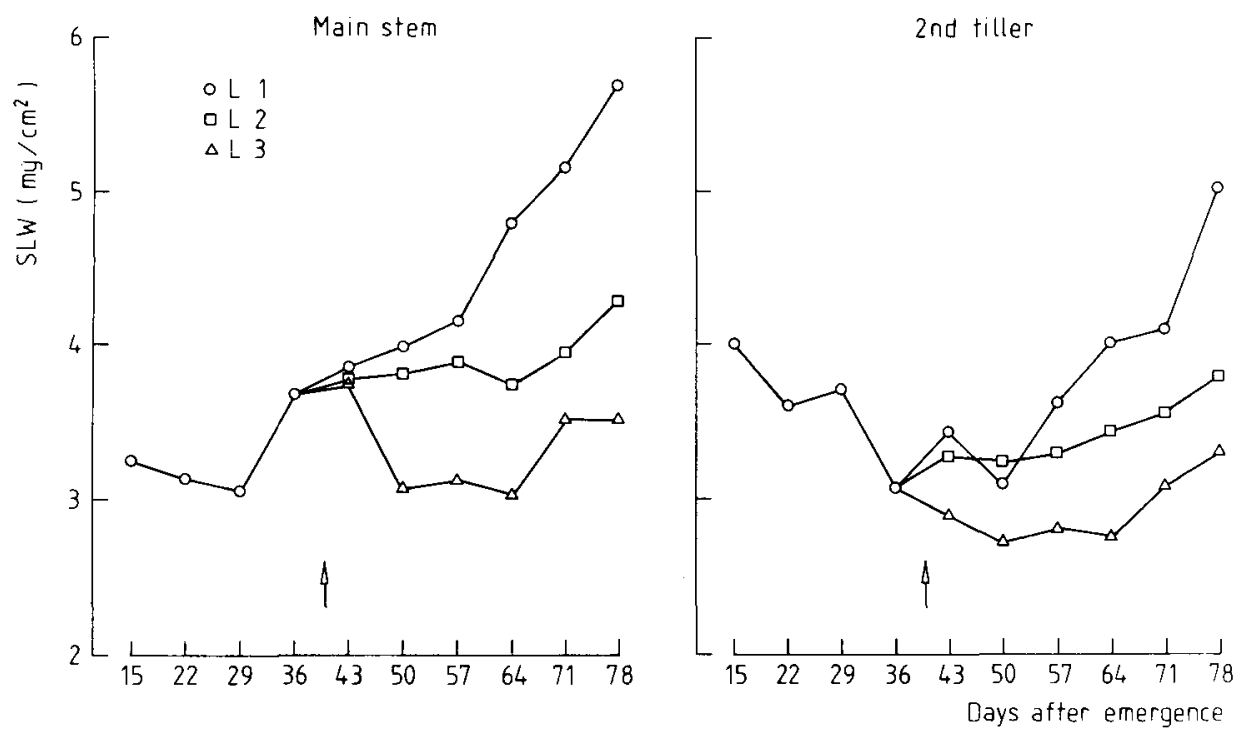

Fig. 1. Specific leaf weight (SLW) in the pre-floral growth period at main shoot and second tiller at three light intensities. Arrows show start of L2 and L3.

\section{Shoot and ear growth}

Figure 2 shows, per light intensity, the dry weights of main stem and second tiller and the ear dry weights during the first 78 days of the growth period (the first tillers were always heavier than the second tillers, and the remaining shoots always weighed less than the second tillers). The increase in dry weight per shoot strongly depended on the light level. In the period from day 40 (establishment of light intensities) to day 78 (last periodical harvest) the dry weight of the main stems, ears included, of L1 and L3 plants increased by 59 and $22 \mathrm{mg}$ per day, respectively; for the second tillers these values were 36 and $18 \mathrm{mg}$ per day.

After day 70 the ears could be separated from the shoots (Fig. 2). On day 78 the dry weights per ear of the main stems were 518 and $209 \mathrm{mg}$ for L1 and L3 plants, respectively; the corresponding weights for the second tillers were 82 (L1) and 73 (L3) $\mathrm{mg}$. However, by then the growth stages in the different light intensities were asynchronous (Table 1), and therefore the ear weights of L2 and L3 plants are undervalued.

Dry weight of aboveground plant parts, root dry weight, harvest index (HI) and yield components

Reducing the light intensity delayed development (Table 1) and decreased the dry weight per plant. The yield components were also affected (Table 3 ). The increase in dry weight of aboveground plant parts, from the establishment of the light inten- 


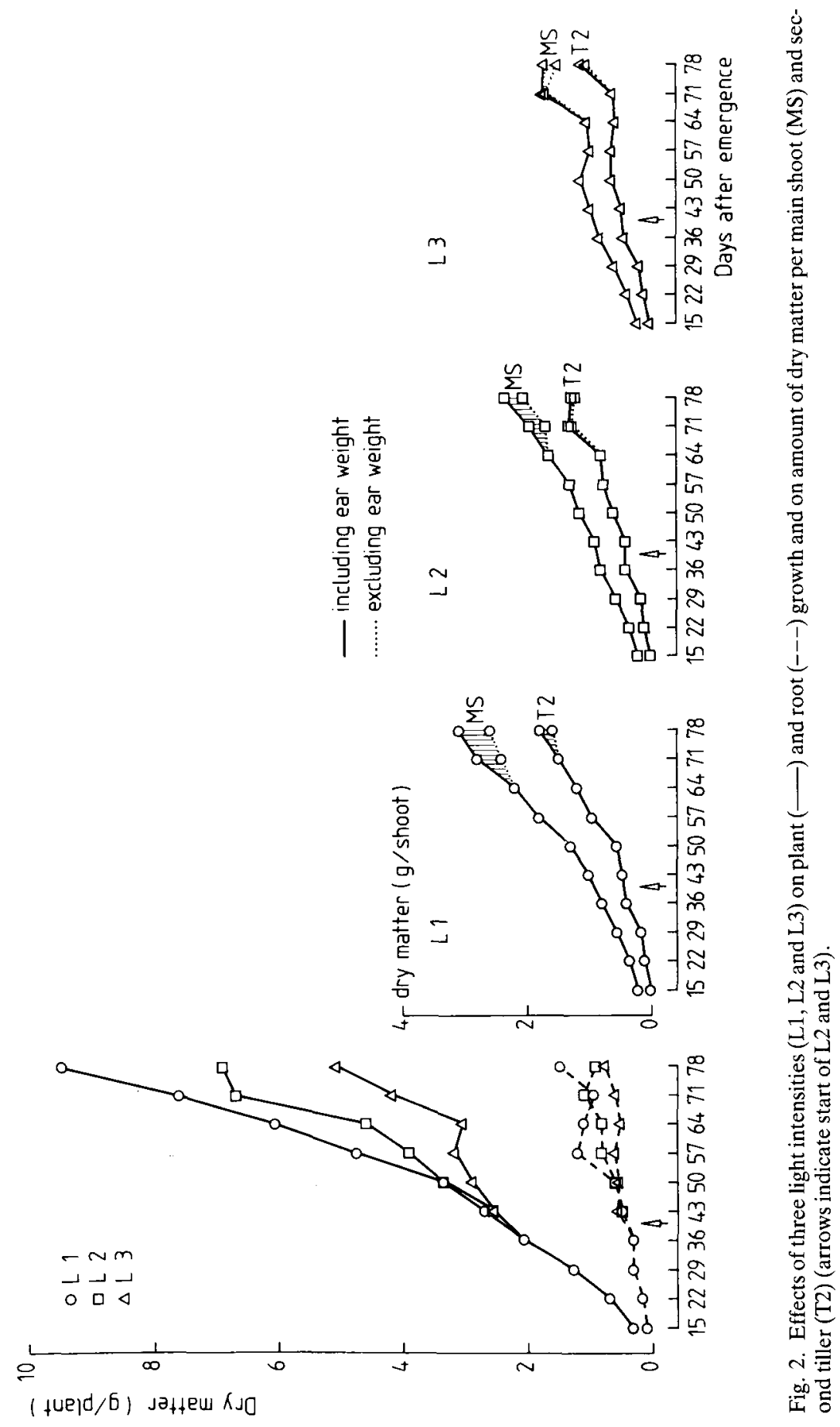


sities to the end of the anthesis of L1 plants, was $187 \mathrm{mg}$ per day per L1 plant and 72 mg per day per L3 plant (Fig. 2).

In the same period the dry weight of the roots (Fig. 2) increased by 26 (L1) and 10 (L3) mg per plant per day.

The shoot/root ratio at day 64 , when no roots had yet decayed, differed significantly $(P<0.001)$ between the light intensities. The ratios for L1, L2 and L3 plants were $5.36,5.99$ and 6.48 , respectively.

Relative and absolute root production were smaller at lower light intensity.

Table 3 demonstrates that the effect of light intensity on total dry matter yield and kernel yield can be large. A reduction of the light level by $33 \%$ (L1 compared with L2) hardly affected the yields, but reducing the light level to $71 \%(\mathrm{~L} 1 \mathrm{com}-$ pared with L3) lowered total dry matter yield and grain yield with $37 \%$ and $47 \%$, respectively.

The harvest index was affected negatively by a strong reduction in light (L3; Table 3). The L3 plants had a tendency to lodge.

Yield components were also influenced strongly by light reduction. Decreasing the light intensity by $71 \%$ resulted in the number of shoots decreasing by about $22 \%$ (compared with L1).

The lower kernel yield at L3 plants induced by light reduction was mainly brought about by fewer ears per plant, fewer kernels per ear and a lower 1000-grain weight.

\section{Water-soluble carbohydrates (WSC)}

Figure 3 shows the content of WSC in the stems and leaves of the main shoots. Light greatly influenced this content. During stem elongation and the development of leaves and ears, the WSC content fell at all light intensities. This fall was sharper and more prolonged at the low light intensity. At the high light intensity (L1) this fall lasted seven days. Thereafter, the content of WSC increased again, to attain a maximum of $36 \%$ in the stems and $23 \%$ in the leaves by day 78 . In the plants in the lower light intensities the WSC content was lower. On day 78, the WSC of the L2 plants had nearly regained its former peak, but the WSC of the L3 plants was well below its initial peak. At final harvest the WSC contents of the stems and leaves of the main shoots of L1, L2 and L3 plants were $7.9 \%, 5.1 \%$ and $1.2 \%$, respectively (not shown). These values of WSC content at final harvest were considerable, both for L1 and L2 plants. This, plus the high kernel weights, implies that the kernels had a limited storage capacity.

The trends in the amount of WSC (in mg) per main shoot are also presented in Figure 3. Averaged over all light intensities during the pre-anthesis phase, $83 \%$ of total WSC in the main shoots was found in the stems and $17 \%$ in the leaves.

During stem elongation and leaf and ear development the total amount of WSC in stems plus leaves decreased. It subsequently recovered, though the rate and magnitude of WSC accumulation varied between light treatments, and there were large differences between the treatments by day $78: 1100 \mathrm{mg}$ per main shoot of the L1 plants, compared with 501 and $198 \mathrm{mg}$ per main shoot for L2 and L3 plants, re- 


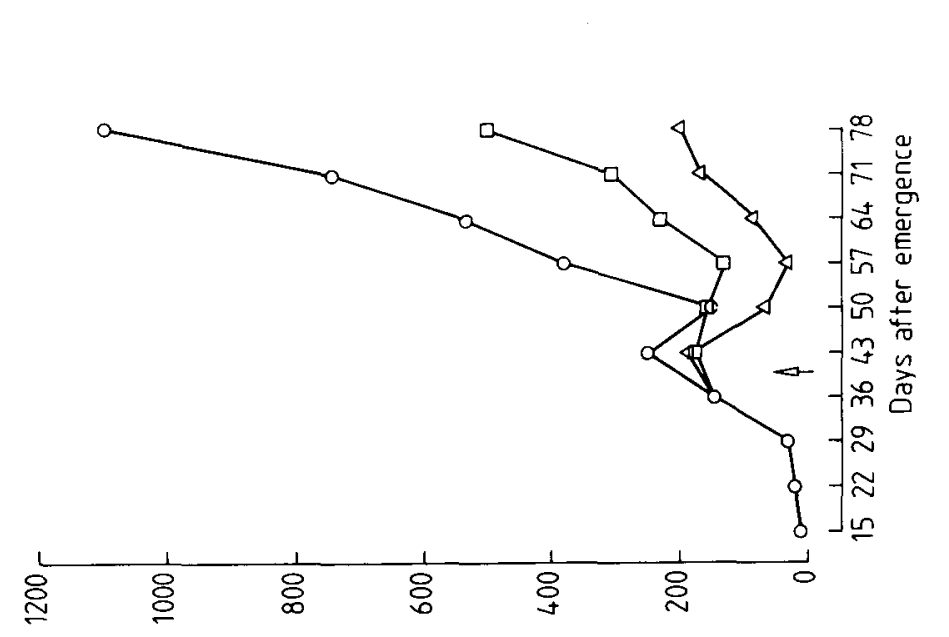

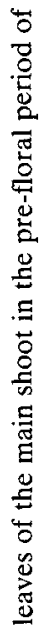

(fooys Uiew/6w) JSM
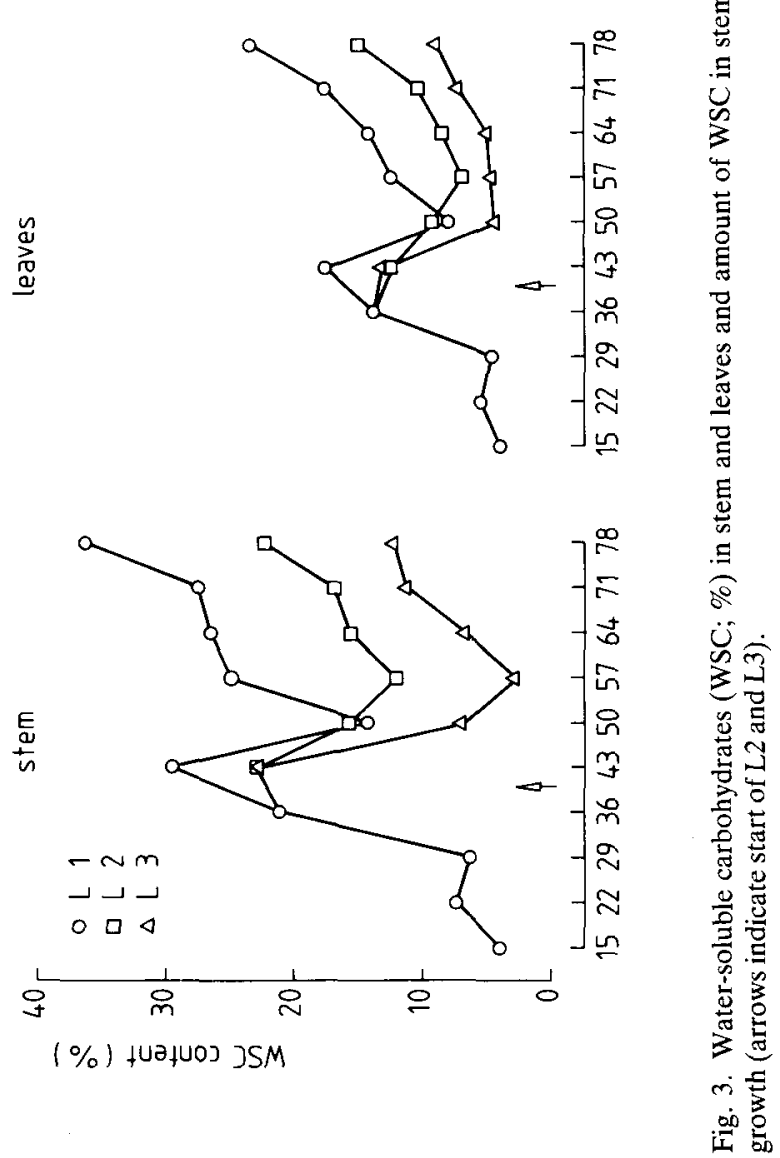


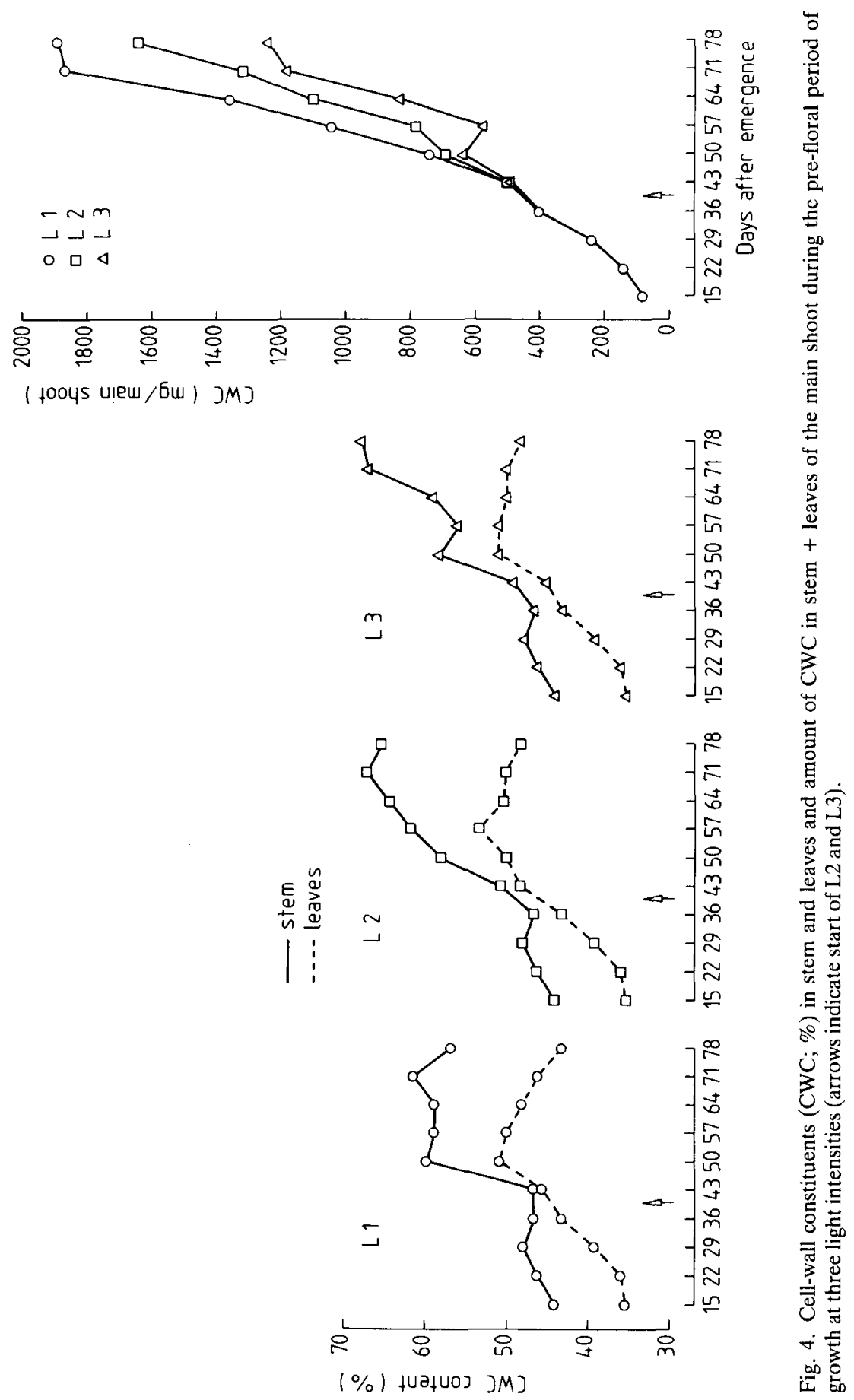


spectively. On day 144 the corresponding figures were 169,91 and $31 \mathrm{mg}$ per main shoot.

\section{Cell-wall constituents $(C W C)$}

The content and amount of CWC (Fig. 4) were measured in the stems and leaves of main shoots only. Reducing the light level increased the CWC content.

Averaged over the three light intensities, $49 \% \mathrm{CWC}$ was found in the leaves in the period from day 43 to day 78 and $61 \%$ was found at final harvest. After day 50 (GS 35) the decrease in CWC content of the leaves was greater in L1 plants than in L2 and L3 plants. At final harvest, hardly any differences in CWC content of the leaves were measured. Averaged over the light intensities, the CWC content increased by $20 \%$ between days 78-144.

A much higher CWC content was measured in the stems. Between days 43-78, the CWC content of the stems, averaged over the light levels, was $59 \%$. At final harvest this content was $83 \%$. On day 78 the difference between L1 on the one hand and L2 and L3 on the other hand was about $15 \%$, and at final harvest it was $5 \%$. Averaged over the light levels, the CWC content increased by over $28 \%$ from day 78 to day 144 .

On day 78 the amounts of CWC in leaves of main shoots (including dead leaves) were 267,294 and $276 \mathrm{mg}$ per main shoot for L1, L2 and L3 plants, respectively. On day 144 , the CWC values per main stem were 284,241 and $232 \mathrm{mg}$.

There was a marked difference between treatments in the amounts of CWC in the stems on day 78. On that day, the values for CWC per main stem were 1623 , 1341 and $959 \mathrm{mg}$ for L1, L2 and L3 plants, respectively. However, the growth stages were asynchronous on that day (Table 1), and therefore the amounts of CWC in L2 and L3 plants are undervalued.

In stems and chaff combined, the CWC values per main stem were, on average, 1590,1394 and $1081 \mathrm{mg}$ for L1, L2 and L3 plants, respectively, at final harvest.

\section{Discussion}

Light intensity greatly influences the rate of development, spikelet development and growth of spring barley (Tables 1, 2, 3; Fig. 2). Via photosynthesis the light intensity affects the amount of carbohydrates available for growth of crop and kernels.

The effect of light intensity could be seen in a slower rate of development (Table 1) and ripening. Although by day 144 all plants were harvest-ripe, they did differ in moisture content (Table 3). This indicates that in the L2 and L3 plants, grain filling was slower and ripening was delayed. The prolonged presence of green leaves at low light intensity can be attributed to the same effect. Spiertz (1974) also observed that the leaves of spring wheat died less rapidly at low light intensities. Under field conditions the effects of light intensity on development will not be so great as in this experiment: day-length (Cottrell et al., 1982) and temperature (Gallagher et al., 1976) control this process much more. 
Another result of reduction of light intensity was a lower specific leaf weight (Fig. 1). This is an often observed occurrence at lower light intensities. It indicates that the leaves produce fewer assimilates and have a smaller surplus of carbohydrates for transportation (Fig. 3). Light saturation is also attained sooner in such leaves than in leaves grown under high light intensity.

The effect of light intensity on ear development was clear (Table 2). Competition for carbohydrates between shoot and ear growth could have been important here. A decrease in the amount of WSC (Fig. 3) on day 43 (GS 34) appeared to be accompanied by a sharp increase in amount of CWC (Fig. 4). This suggests that a large amount of carbohydrates was consumed for stem growth. In a field experiment with spring wheat, Thome \& Kühbauch (1985) also found a decrease in content and amount of WSC just before and during anthesis. The decrease and recovery of WSC level (Fig. 3) took about 14 days for L1 plants, but these days fell in the important period of spikelet development (Table 1). In L2 plants and L3 plants, this period of decrease and recovery was three and four weeks longer, respectively, while in L3 plants the initial WSC level was never regained. Fig. 4 shows that the WSC level in L3 plants was inadequate for stem growth and respiration during the period from day 50 to day 64 . This was also expressed in the tendency of L3 plants to lodge.

The content (\%) of WSC in the stems of all plants at anthesis, for main shoot, first and second tiller, correlated well $(r=0.68, P<0.025)$ with number of kernels per ear at final harvest.

Besides competition between shoot and ear growth, other factors probably also affect the number of kernels per ear. Hanif \& Langer (1972) showed that assimilate supply to and growth of the top spikelets in wheat before anthesis was limited by a reduction in number and width of the vascular bundles, leading to these spikelets. Something similar was described for barley by Kirby \& Rymer (1974). They suggested that the death of terminal spikelets might be caused by competition from the basal and mid spikelets of the ear, which take advantage of an earlier established vascular system.

Although it is assumed that hormonal processes are involved in grain set (Evans et al., 1972) the effect of carbohydrate supply cannot be ignored. Both Spiertz (1977) and Wardlaw (1970) observed a strong reduction in number of kernels per ear in wheat at low light intensities, just after anthesis. In a field experiment with barley, Willey \& Holliday (1971) found that shading before anthesis reduced the number of spikelets per ear, whereas shading after anthesis had hardly any effect. In the present experiment, the numbers of fertile spikelets at anthesis, averaged over main stem, first and second tillers, were 30,31 and 25 for L1, L2 and L3 plants, respectively. Of these spikelets, $94 \%, 88 \%$ and $94 \%$ actually set grains. Gallagher (1979) stated that under normal conditions, about $95 \%$ of the fertile spikelets of barley will bear grains, whereas the corresponding figure for wheat is about $80 \%$. The observations done by Lingle \& Chevalier (1985) on barley showed that in the phase of grain set the vascular system is well developed; therefore, by influencing the level of carbohydrates, the level of light intensity can limit grain set. In the present experiment, however, the grain set did not seem to be much influenced by a reduction in light during the phase of grain set (Table 2). 
The small difference between L1 and L2 plants in kernel yield and yield components was remarkable (Table 3 ). Reducing the light intensity by $33 \%$ (L1 to L2) depressed kernel yield by $11.8 \%$ and the number of ears per plant by $6.1 \%$. The number of kernels per ear $(2.2 \%)$ and 1000 -grain weight $(2.9 \%)$ were hardly affected. The considerable amounts of WSC in the plants at final harvest is of importance here. For L2 plants, and even more so for L1 plants, these amounts suggest a limitation in storage capacity; this is corroborated by very high (for $\mathrm{cv}$. Trumpf) 1000-grain weights (Table 3). The even larger amounts of WSC at final harvest in the tillers, which had fewer kernels per ear (Table 2), are clear evidence of the limited storage capacity.

The difference in grain yield between L1/L2 and L3 plants was much larger. The kernel yield of L3 plants was $44 \%$ lower than that of L1/L2 plants. All yield components contributed to this appriceable reduction (Table 3), but 1000-grain weight was the most important. In L3 plants it was not the number of kernels per ear (Table 3) that was the first limiting factor for kernel yield, but rather the production of carbohydrates, which is essential for a high kernel weight. This can also be deduced from the very low amounts of WSC in stems and leaves (MS+T2) at final harvest.

The light intensity may have affected 1000 -grain weight by influencing the growth of the ovary in the phase of ear growth and floral development (Willey \& Holliday, 1971; Kirby, 1974) and by influencing cell division and cell expansion (number of endosperm cells) during grain set (Feucht \& Hofner 1983; Wardlaw, 1970). These processes mainly determine the potential size of the kernel. The supply of carbohydrates and growth rate of the kernel during grain filling will determine the size of the initiated grain. The limited production of carbohydrates in the L3 plants (Fig. 3) negatively affected the three aspects mentioned above. This resulted in L3 plants having a lower 1000-grain weight. The magnitude of the influence of each individual aspect cannot be ascertained.

A strong reduction in light intensity (L3) reduced the number of ears per plant (Table 3) and the straw sturdiness of the stems. Willey \& Holliday (1971) also found fewer ears per $\mathrm{m}^{2}$ in reduced light. Obviously, only the most dominant shoots are capable of bearing fertile ears when a limited supply of carbohydrates is available.

From the harvest index (HI, Table 3 ) it can be seen that the L2 crop functioned more efficiently than the L1 and L3 crops.

Most of the carbohydrates for grain filling were supplied by photosynthesis in the post-anthesis period (Fig. 3). Reducing the light intensity decreased the WSCCWC ratio. In L3 plants the translocation of WSC from stems and leaves to the kernels was considerable: $1.2 \%$ of WSC was left in the plant parts at final harvest. The demand from the kernels for WSC could not be met. In the L3 plants the production of WSC was too small for the growth, maintenance and filling of the grain.

\section{Acknowledgements}

The authors are indebted to Prof. P. C. Struik and Ir N. M. de Vos for their valuable comments and critical reading of the manuscript. 


\section{References}

Appleyard, M., E. J. M. Kirby \& G. Fellowes, 1982. Relationships between the duration of phases in the pre-anthesis life cycle of spring barley. Australian Journal of Agricultural Research 33: 917-925.

Cottrell, J. E., J. E. Dale \& B. Jeffcoat, 1982. The effects of daylength and treatment with gibberellic acid on spike initiation and development in Clipper barley. Annals of Botany 50: 57-68.

Dougherty, C. T., K. R. Roony, W. R. Scott \& R. H. W. Langer, 1975. Levels of water-soluble carbohydrate in the pre-anthesis ear of wheat, and grain set per spikelet. New Zealand Journal of Agricultural Research 18: 351-356.

Evans, L. T., J. Bingham \& M. A. Roskins, 1972. The pattern of grain set within ears of wheat. Australian Journal of Biological Science 25: 1-8.

Feucht, D. \& W. Höfner, 1983. Eine verbesserte Methode zur Bestimmung der Anzahl von Endospermzellen in Weizenkörnern. Zeitschrift für Pflanzenernährung und Bodenkunde 146: 697-704.

Fisher, R. A. \& Y. M. Stockman, 1980. Kernel number per spike in wheat (Triticum aestivum L.): responses to pre-anthesis shading. Australian Journal of Plant Physiology 7: 169-180.

Gallagher, J. N., 1979. Ear development: processes and prospects. In: Spiertz, J. H. J. \& Th. Kramer (Eds), Crop physiology and cereal breeding, p. 3-9. Proceedings of a Eucarpia Workshop. Pudoc, Wageningen.

Gallagher, J. N., P. V. Biscoe \& R. K. Scott, 1976. Barley and its environment. IV. Growth and development in relation to yield. Journal of Applied Ecology 13: 563-583.

Goering, H. K. \& P. J. van Soest, 1970. Forage fiber analyses (apparatus, reagents, procedures, and some applications). Agriculture Handbook No. 379, p. 1-20. United States Department of Agriculture.

Hanif, M. \& R. H. M. Langer, 1972. The vascular system of spikelet in wheat (Triticum aestivum). Annals of Botany 36: 721-727.

Kirby, E. J. M. \& J. L. Rymer, 1974. Development of the vascular system in the ear of barley. Annals of Botany 38: 565-573.

Kirby, E. J. M., 1974. Ear development in spring wheat. Journal of Agricultural Science (Cambridge) 82: 437-447.

Kirby, E. J. M., 1977. The growth of the shoot apex and the apical dome of barley during ear initiation. Annals of Botany 41: 1297-1308.

Lingle, S. E. \& P. Chevalier, 1985. Development of the vascular tissue of the wheat plant and barley caryopsis as related to the rate and duration of grain filling. Crop Science 25: 123-128.

Rawson, H. M. \& L. T. Evans, 1970. The pattern of grain growth within the ear of wheat. Australian Journal of Biological Science 23: 753-764.

Sofield, I., L. T. Evans, M. G. Cook \& I. T. Wardlaw, 1977. Factors influencing the rate and duration of grain filling in wheat. Australian Journal of Plant Physiology 4: 785-797.

Spiertz, J. H. J., 1974. Grain growth and distribution of dry matter in the wheat plant as influenced by temperature, light energy and ear size, Netherlands Journal of Agricultural Science 22: 207-220.

Spiertz, J. H. J., 1977. The influence of temperature and light intensity on grain growth in relation to carbohydrate and nitrogen economy of the wheat plant, Netherlands Journal of Agricultural Science 25: 182-197.

Thome, U. \& W. Kühbauch, 1985. Change in the carbohydrate pattern in cell content of wheat stems during grain-filling. Zeitschrift für Acker-und Pflanzenbau 155: 253-260.

Wardlaw, I. F., 1970. The early stages of grain development in wheat: response to light and temperature in a single variety. Australian Journal of Biological Science 23: 765-774.

Willey, R. W. \& R. Holliday, 1971. Plant population and shading studies in barley. Journal of Agricultural Science (Cambridge) 77: 445-452.

Zadoks, J. C., T. T. Chang \& C. F. Konzak, 1974. A decimal code for growth stages of cereals. Weed Research 14: 415-421. 